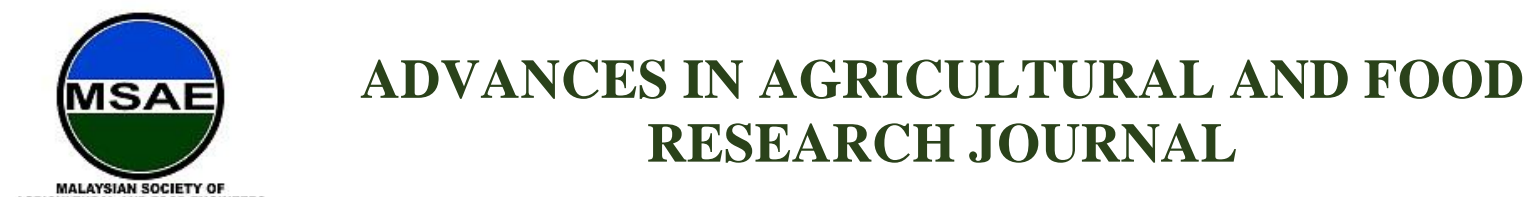

HH PUBLISHER

Short Communication

\title{
Effect of Light Emitting Diode (LED) Spectrum at Seedlings Production for Optimal Growth on Different Type of Lettuce in MARDI Plant Factory
}

\author{
Mohamed Hafeifi Basir ${ }^{1 *}$, Intan Nadhirah Masri ${ }^{2}$ \\ ${ }^{1}$ Horticulture Research Centre, Malaysian Agriculture Research and Development Institute (MARDI), 43400, \\ Serdang, Selangor, hafeifi@mardi.gov.my \\ ${ }^{2}$ Soil Science, Water and Fertilizer Research Centre, MARDI, 43400, Serdang, Selangor, \\ intannadhirah@mardi.gov.my \\ *Corresponding author: Mohamed Hafeifi Basir, Horticulture Research Centre, Malaysian Agriculture \\ Research and Development Institute (MARDI), 43400, Serdang, Selangor; hafeifi@mardi.gov.my
}

\begin{abstract}
Seedling production is a crucial part of the production of fresh vegetables in a plant factory. Light is one of the necessities for plants to produce a healthy seedling before being transplanted to the production area. Different light formulations resulted in different growth performances of the plant. Hence, this study was conducted to aim for suitable light formulation on various types of lettuce in the MARDI Plant Factory. The study was conducted in two stages: 1) seedling production and 2) production area. Treatments were evaluated at the seedlings' production stage using the split-plot experimental design with four replications. LED light treatments (LT) was the main factor with the various ratio of spectrum colour of Red (R), Blue (B), Green (G) and full spectrum. (LT 1; 5R:1B, LT 2; 1R:1B, LT 3; 1R: 2B, LT 4; 2R:1B, LT 5; 4R:1B:1G and LT 6; Full spectrum as control). The sub-factor was lettuce variety (V1; Butterhead, V2; Green Coral, V3; Red Coral and V4; Mini Cos). Variables measured at seedlings production were seed germination. Growth biomass and SPAD value were evaluated in the production area. At seedlings production, the full spectrum lighting shows significant seeds germination percentage compared to other LED lighting, and V1 performed well on germination percentage and time compare to other varieties. The interaction between light treatments and lettuce was observed on the leaf numbers, shoot fresh weight, leaf area, and the shoot-root ratio at the production area. LT 1 and LT 5 on butterhead and green coral significantly affected the number of leaves and leaf area, which were relatively influenced by light quality and ambient temperature. The yield on green coral lettuce grown under LT 1, LT 2, and LT 5 was significantly higher than others. However, plant biomass and SPAD value for all treatments were not significantly different. The allometry of plant was expressed on a shoot-root ratio with LT 2 on green coral shows a significantly higher shoot-root ratio than other treatments. The study's findings showed that light treatment with Red and Blue LED ratio of 5:1, 1:1, and Red, Blue, and Green LED ratio of 4:1:1 light arrangement on the seedling's productions provided optimal growing conditions in the production area butterhead and green coral lettuce in MPF cultivation.
\end{abstract}


Keywords: LED; lettuce; plant factory; seedling production

Received: $25^{\text {th }}$ July 2021

Received in revised form:

Accepted: $25^{\text {th }}$ August 2021

Available Online: $14^{\text {th }}$ September 2021

Citation: Basir MH \& Masri IN. Effect of light emitting diode (LED) spectrum at seedlings production for optimal growth on different type of lettuce in MARDI plant factory. Adv Agri Food Res J 2021; 2(2): a0000229.

\section{Introduction}

Production of high-value vegetables in Malaysia focused on highlands, especially in Cameron Highlands (Barrow, 2009). Increasing demand for the commodity leads to uncontrolled development of new areas to produce more yield, resulting in environmental pollution such as groundwater sediment, agrichemical wastage, and manure-enriched runoff (Charlton, 1987). To reduce the impact of environmental pollution on highlands agriculture, production in lowland areas using indoor farming known as plant factory is vital.

A plant factory is a facility for vegetable production using the multilayer hydroponic system (MHS) with artificial lighting in a thermally insulated and nearly airtight warehouselike structure (Kozai, 2013). Two types of standard hydroponic technology were used in plant factories: Nutrient Film Technique (NFT) and Deep Flow Technique (DFT). NFT is a hydroponic planting system where the plant grows in a channel or gully, contain a thin layer of water with dissolved nutrient that move through the plant root in soilless condition. The DFT system is similar to NFT but contains a $4-5 \mathrm{~cm}$ deep nutrient solution. MARDI developed the plant factory as a model for a new agricultural approach for indoor farming. The plant factory was built on a modular structure, using green materials that are energysaving and environmentally friendly. The size of the production area is 30' (width) $\times 80^{\prime}$ (length) $\times 20^{\prime}$ (height), which can produce 16,000 plants per cycle on seven layers deep flow technique hydroponic systems structure. Consistent production in the plant factory requires an efficient and effective seedlings production system to produce high-quality vegetables. Seedling's production was placed in the multilayer nursery area. The nursery is required to save time, produce healthy seedlings before being transplanted to the production area. The growing condition, such as light condition, nutrient requirement, and the plant factory environment designed to fulfill the plant's growing condition and needs to grow in the plant factory.

Light is essential for plant growth and development. In the plant factory nursery, the selection of light sources must be cost-effective and of high performance for the plant to mature before being transplanted to the production area. LED lamps' spectral distribution or light quality affects plant growth and development (Jokinen et al., 2012; Liu et al., 2012; Massa et al., 2008; Mitchell et al., 2012; Morrow, 2008). Visible light is crucial for photosynthetically active radiation $(400 \mathrm{~nm}-00 \mathrm{~nm})$. With a wavelength of $600-700 \mathrm{~nm}$, red light is most effective for promoting plants' photosynthesis. However, blue light with a 400 
$500 \mathrm{~nm}$ wavelength is necessary mainly for photomorphological and phytochemical reasons for a given amount of electric energy consumption (Kozai, 2013). Additional green light for lower leaf absorption can be helpful for densely populated plant communities (Kozai, 2012). Daylight integral (DLI) is the amount of light intensity and photoperiod to optimize lettuce planted in the plant factory and reduce operational costs.

Malaysia produced 51 tonnes in 3000 hectares of lettuce in 2019 (DOA, 2019) and still importing 9,000 tonnes, mainly from China and Thailand, which was evaluated at 8.6 million USD (Comtrade, 2019). In the market, lettuce was of high demand was of a looseleaf type such as green coral, red coral, butterhead, and romaine. Lettuce can be produced in the plant factory. The investment in the MARDI Plant Factory (MPF) was projected to be returned in the third year of lettuce production.

This study's main objective is to identify suitable LED light formulation for healthy seedlings in different high-value lettuce varieties. As seedlings production is the most crucial part of the plant factory, the LED must provide optimum light requirements to produce sturdy seedlings, early maturity, and timesaving before transplanted and harvested at the production area. After being transplanted to the production area, the performance of seedlings was recorded to compare with the performance at seedlings production.

\section{Materials and Methods}

The study was done in MPF, Serdang, from April until May 2020. The experimental design was a split plot with four replications. The main factor is the LED light treatments on the nursery stage, and the various lettuce varieties are the subfactor of these experiments. Two stages of planting observation were done. The treatments were tested at the first stage, on the seedlings production shelf, and further observation was done on the second stage at the production area.

\subsection{LED Light Treatments}

The LED light was produced locally by Impressive Edge Sdn. Bhd. (IE) located in Malacca. The LED light was fabricated with different red, blue, and green horticulture diodes from OSRAM with a standard of $121 \mathrm{~cm}$ length per unit. The control treatment was fullspectrum light produced by Samsung Malaysia. Specific features of all light treatments are included in table 1. Photosynthetic Photon Flux Density (PPFD) measures the amount of light to enable photosynthesis on the plant's parts, especially on leaves. 
Table 1. Light treatments features.

\begin{tabular}{|c|c|c|c|c|c|c|}
\hline \multirow{2}{*}{ Light Treatments (LT) } & \multicolumn{3}{|c|}{ Ratio by colour } & \multirow{2}{*}{ Producer } & \multirow{2}{*}{$\begin{array}{c}\text { PPFD at } 25 \mathrm{~cm} \\
\left(\mu \mathrm{mol} / \mathrm{m}^{2} / \mathrm{s}\right)\end{array}$} & \multirow{2}{*}{$\begin{array}{c}\text { Ambient } \\
\text { Temperature } \\
\left({ }^{\circ} \mathrm{C}\right)\end{array}$} \\
\hline & Red & Blue & Green & & & \\
\hline LT 1 & 5 & 1 & 0 & IE & $204-237$ & $28.9-29.1$ \\
\hline LT 2 & 1 & 1 & 0 & IE & $177-198$ & $27.5-27.8$ \\
\hline LT 3 & 1 & 2 & 0 & IE & $165-185$ & $26.9-27.2$ \\
\hline LT 4 & 2 & 1 & 0 & IE & $187-203$ & $27.6-27.8$ \\
\hline LT 5 & 4 & 1 & 1 & IE & $220-241$ & $28.2-28.4$ \\
\hline LT 6 & \multicolumn{3}{|c|}{ Full spectrum } & Samsung & $265-320$ & $27.3-27.6$ \\
\hline
\end{tabular}

\subsection{Lettuce Varieties}

Plants samples were selected based on suitability to grow in the indoor environment with multilayer hydroponics systems. The varieties' selection was based on high-value marketable lettuce, with compact, shorter height $(30-35 \mathrm{~cm})$ and canopy $(35-40 \mathrm{~cm})$. Four types of plants sample were selected based on the criteria. The varieties are listed in Table 2 .

Table 2. Lettuce treatments varieties.

\begin{tabular}{cccc}
\hline $\begin{array}{c}\text { Lettuce } \\
\text { treatments }\end{array}$ & Type of lettuce & Varieties & Producer \\
\hline V1 & Butterhead & Bravado BB330 & Leckat \\
V2 & Green Coral & Good Luck GL88 & Leckat \\
V3 & Red Coral & Fire Red 923 & Leckat \\
V4 & Mini Cos & Royal Victoria 7337 & Leckat \\
\hline
\end{tabular}

\subsection{Stage 1: Seedlings Production}

Multilayer nutrient film technique (NFT) hydroponics shelf with the dimension of $181 \mathrm{~cm}$ (height) $\times 121 \mathrm{~cm}$ (length) $\times 121 \mathrm{~cm}$ (width) were used as seedlings productions (Figure 1). The shelf with the dimension of $30 \mathrm{~cm}$ (width) $\times 100 \mathrm{~cm}$ (length) $\times 5 \mathrm{~cm}$ (height) with three layers was built with two compartments. Two units of LED light treatments were placed on each compartment. Every compartment was partitioned by using a solid plastic reflector. Every compartment will have lettuce treatments varieties. The hydroponic sponge with $1 \mathrm{~cm}^{3}$ in a cluster of 50 units was used as growing media. The seeds were placed on the sponge one each. So, every replication in this phase of experiments was 50 samples. The LED treatments were standardized at 0 hours (0-3 days after sowing (DAS)), 3 hours (4-7 DAS), and 6 hours (7-16 DAS). Hydroponic solution's hydrogen concentration $(\mathrm{pH})$ and electrical conductivity (EC) were set at $5.5-65$ and $0.5-1.00 \mathrm{mS} / \mathrm{cm}$. The air temperature was set at $24-28^{\circ} \mathrm{C}$, and the carbon dioxide concentration ranged from $440 \mathrm{ppm}-560 \mathrm{ppm}$. Parameters observed during seedlings production were seedlings germination percentage, days of seed germination, day of cotyledon leaf appearance, and day of actual leaf appearance. 


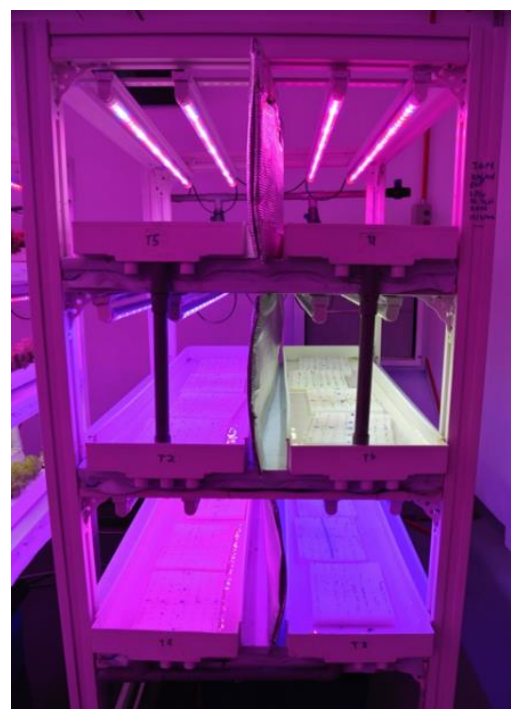

Figure 1. Seedling's production area was tested with different combinations of light treatment in a multilayer NFT hydroponic system.

\subsection{Stage 2: Production Area}

The plants' samples from stage 1 were transplanted to the production area. The production area uses a multilayer deep flow technique (DFT) with a hydroponic system and a dimension of $486 \mathrm{~cm}$ (width) $\times 305 \mathrm{~cm}$ (length) $\times 121 \mathrm{~cm}$ (height). At this stage, the growth requirement such as lighting, nutrient, and environmental conditions was set at the same range for every treatment. The LED lighting used was red and blue, with a ratio of $4: 1$. The day length integrals (DLI) on light requirement was 8 hours (0-7 days after transplanting (DAT)), 10 hours (8-14 DAT), and 12 hours (15-30 DAT). Hydroponic solution's hydrogen concentration $(\mathrm{pH})$ and electrical conductivity (EC) were set at $5.5-65$ and $1.50-1.90 \mathrm{mS} / \mathrm{cm}$. The air temperature was set at $24-28^{\circ} \mathrm{C}$, and the carbon dioxide range was $440 \mathrm{ppm}-560$ ppm. Parameters measured on plant samples during stage 2 were leaf number, leaf area, shoot fresh and dry weight, root fresh and dry weight, shoot to root ratio, SPAD value and specific leaf weight. The measurements were recorded at harvest on 30 DAT. The SPAD value was measured using SPAD 502 Plus-Konica Minolta. The shoot and dry root weight were measured after 48 hours of $70^{\circ} \mathrm{C}$ drying in a lab-scale oven. The shoot and root ratios were calculated using the formula below.

$$
A=\frac{a}{b}
$$

where, $A=$ shoot to root ratio

$\mathrm{a}=$ dry weight of shoot

$b=$ dry weight of root 
Leaf area was measured using the LI 3100 leaf area meter model. Specific leaf weight was calculated using the formula below.

$$
\mathrm{C}=\frac{\mathrm{c}}{\mathrm{d}}
$$

Where, $\mathrm{C}=$ specific leaf weight

$\mathrm{c}=$ dry weight of shoot

$\mathrm{d}=$ leaf area

\subsection{Data Analysis}

The data were analysed by analysis of variance (ANOVA) using Statistical Analysis Software (SAS) version 9.4. All significant values were analysed using Least Significance Difference (LSD) at a significant level of $P \leq 0.05$.

\section{Results}

The percentage of germination of the main factor on LT $6(70.50 \%)$ was significantly different from other treatments from the study. V1 (84.58\%) was significantly different from other varieties (Table 3). No significant differences were found on the day to germinate, the day to cotyledon leaf appearance, and the day to actual leaf appearance. However, V1 was significantly differenced with other varieties on least day to germinate, day to cotyledon leaf appearance, and day to true leaf appearance. No interaction between LED treatments and varieties on the parameters at the seedlings production stage.

Table 3. Stage 1: Seedlings productions.

\begin{tabular}{ccccc}
\hline Treatments & $\begin{array}{c}\text { Germination } \\
\text { percentage }(\%)\end{array}$ & $\begin{array}{c}\text { Seed germinates } \\
\text { (day) }\end{array}$ & $\begin{array}{c}\text { Cotyledon leaf } \\
\text { appearance (day) }\end{array}$ & $\begin{array}{c}\text { True Leaf } \\
\text { Appearance (day) }\end{array}$ \\
\hline Light Treatments & $61.38^{\mathrm{b}}$ & 2.88 & 5.88 & 16.38 \\
LT 1 & $60.63^{\mathrm{b}}$ & 3.13 & 6.19 & 16.56 \\
LT 2 & $62.25^{\mathrm{b}}$ & 3.00 & 5.81 & 16.13 \\
LT 3 & $63.25^{\mathrm{b}}$ & 3.31 & 6.13 & 16.50 \\
LT 4 & $63.50^{\mathrm{b}}$ & 2.94 & 6.00 & 16.19 \\
LT 5 & $70.50^{\mathrm{a}}$ & 3.13 & 5.88 & 0.56 \\
LT 6 & 5.19 & 0.66 & 0.63 & $13.21^{\mathrm{b}}$ \\
P $\leq 0.05$ (LSD) & $84.58^{\mathrm{a}}$ & $2.00^{\mathrm{c}}$ & & $17.21^{\mathrm{a}}$ \\
Varieties & $41.08^{\mathrm{c}}$ & $3.67^{\mathrm{a}}$ & $4.79^{\mathrm{d}}$ & $15.50^{\mathrm{b}}$ \\
V1 & $64.00^{\mathrm{b}}$ & $2.83^{\mathrm{b}}$ & $6.25^{\mathrm{b}}$ & $17.33^{\mathrm{a}}$ \\
V2 & $64.67^{\mathrm{b}}$ & $3.75^{\mathrm{a}}$ & $5.67^{\mathrm{c}}$ & 0.58 \\
V3 & 4.55 & 0.42 & $7.21^{\mathrm{a}}$ & $\mathrm{ns}$ \\
V4 & & & 0.51 & $\mathrm{~ns}$ \\
$\mathrm{P} \leq 0.05$ (LSD) & $\mathrm{ns}$ & $\mathrm{ns}$ & &
\end{tabular}


Table 4. Stage 2: Leaf number, total leaf area, specific leaf weight at the production area.

\begin{tabular}{|c|c|c|c|}
\hline Treatments & Leaf number & $\begin{array}{c}\text { Total leaf area } \\
\left(\mathrm{cm}^{2}\right)\end{array}$ & $\begin{array}{c}\text { Specific Leaf weight } \\
\left(\mathrm{mg} / \mathrm{cm}^{2}\right)\end{array}$ \\
\hline \multicolumn{4}{|l|}{ Light Treatments } \\
\hline LT 1 & $17.67^{\mathrm{a}}$ & $490.06^{\mathrm{b}}$ & 3.62 \\
\hline LT 2 & $15.69^{\mathrm{b}}$ & $491.11^{b}$ & 3.89 \\
\hline LT 3 & $14.10^{\mathrm{c}}$ & $488.78^{b}$ & 3.72 \\
\hline LT 4 & $15.31^{\mathrm{bc}}$ & $496.08^{\mathrm{ab}}$ & 3.92 \\
\hline LT 5 & $17.33^{\mathrm{a}}$ & $519.66^{\mathrm{a}}$ & 3.87 \\
\hline LT 6 & $14.98^{\mathrm{bc}}$ & $383.63^{c}$ & 4.25 \\
\hline $\mathrm{P} \leq 0.05(\mathrm{LSD})$ & 1.57 & 25.48 & 1.65 \\
\hline \multicolumn{4}{|l|}{ Varieties } \\
\hline V1 & $18.50^{\mathrm{a}}$ & $611.69^{a}$ & $1.61^{\mathrm{c}}$ \\
\hline $\mathrm{V} 2$ & $15.04^{\mathrm{c}}$ & $543.34^{\mathrm{b}}$ & $3.62^{b}$ \\
\hline V3 & $13.04^{\mathrm{d}}$ & $473.13^{c}$ & $6.12^{\mathrm{a}}$ \\
\hline V4 & $16.81^{\mathrm{b}}$ & $284.72^{\mathrm{d}}$ & $4.15^{b}$ \\
\hline $\mathrm{P} \leq 0.05$ (LSD) & 1.05 & 22.06 & 0.57 \\
\hline $\mathrm{LT}^{*}$ Variety at $\mathrm{P} \leq 0.05$ & $* * *$ & $* * *$ & Ns \\
\hline
\end{tabular}

There was a significant interaction between LT and varieties factors on leaf number and total leaf area parameters (Table 4). However, no significant interaction on specific leaf weight. No significant difference in LT factors on specific leaf weight. V3 is a significantly higher value of specific leaf weight compare to other varieties.

LT 1 and LT 5 with V1 and V4 have higher leaf numbers than others (Figure 2). LT 1 and LT 5 ambient temperatures were higher compared to LT 6. Significant interaction on LT 5 with V1 and V2 compare with other combinations on total leaf area (Figure 3). The least total leaf area was observed on LT 6 and V3.

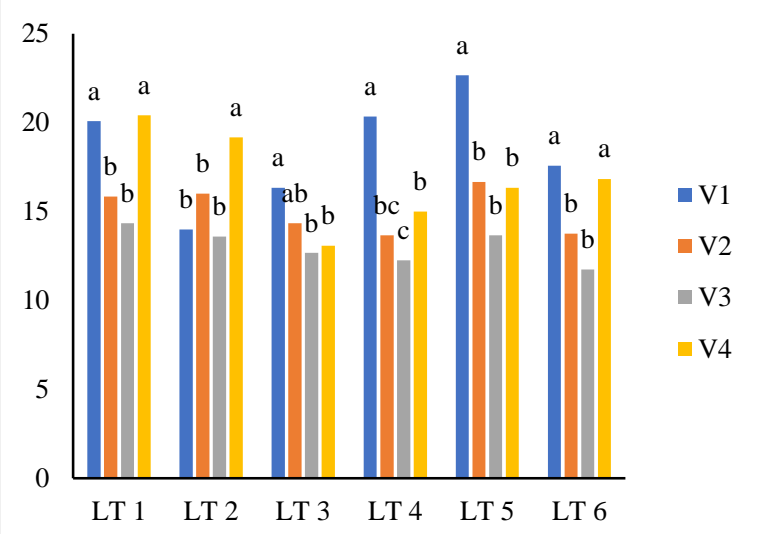

Figure 2. Interaction between LT formulation and lettuce varieties on number of leaves. Means with different letter are significantly different at $P \leq 0.05$ respectively.

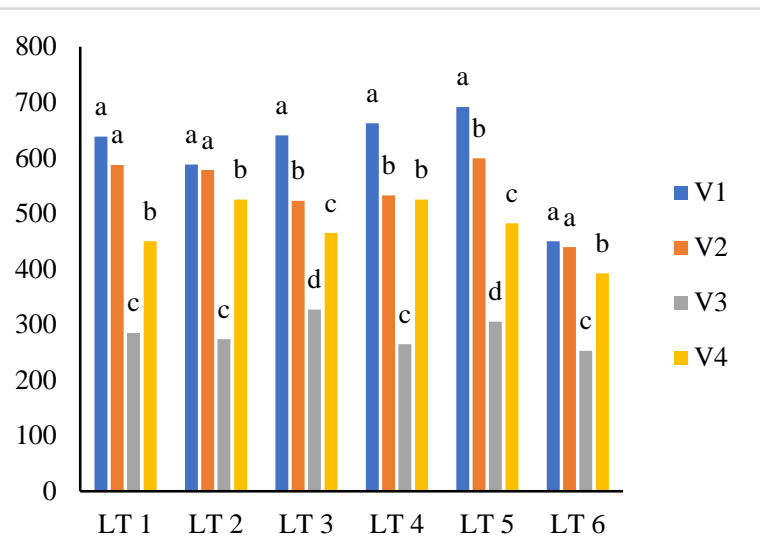

Figure 3. Interaction between LT formulation and lettuce varieties on total leaf area. Means with different letter are significantly different at $P \leq 0.05$ respectively. 
Table 5. Shoot (fresh and dry weight), root (fresh and dry weight), shoot to root ratio, and SPAD value at production area.

\begin{tabular}{|c|c|c|c|c|c|c|}
\hline Treatments & $\begin{array}{c}\text { Shoot fresh } \\
\text { weight }(\mathrm{g})\end{array}$ & $\begin{array}{l}\text { Shoot dry } \\
\text { weight (g) }\end{array}$ & $\begin{array}{c}\text { Root fresh } \\
\text { weight (g) }\end{array}$ & $\begin{array}{c}\text { Root dry } \\
\text { weight (g) }\end{array}$ & $\begin{array}{l}\text { Shoot to } \\
\text { root ratio }\end{array}$ & $\begin{array}{c}\text { SPAD } \\
\text { value }\end{array}$ \\
\hline \multicolumn{7}{|l|}{ Light treatments } \\
\hline LT 1 & $38.48^{\mathrm{a}}$ & 1.56 & $12.45^{\mathrm{ab}}$ & 0.86 & 2.49 & $25.13^{\mathrm{a}}$ \\
\hline LT 2 & $34.88^{\mathrm{a}}$ & 1.74 & $14.09^{\mathrm{a}}$ & 0.59 & 2.95 & $24.92^{\mathrm{ab}}$ \\
\hline LT 3 & $26.47^{\mathrm{b}}$ & 1.65 & $10.61^{b}$ & 0.85 & 3.01 & $24.47^{\mathrm{b}}$ \\
\hline LT 4 & $33.79^{\mathrm{ab}}$ & 1.71 & $10.80^{\mathrm{b}}$ & 0.57 & 2.93 & $25.16^{\mathrm{a}}$ \\
\hline LT 5 & $39.00^{\mathrm{a}}$ & 1.76 & $12.32^{\mathrm{ab}}$ & 0.80 & 2.81 & $24.71^{\mathrm{ab}}$ \\
\hline LT 6 & $31.13^{\mathrm{ab}}$ & 1.56 & $10.83^{b}$ & 0.49 & 3.09 & $23.23^{\mathrm{c}}$ \\
\hline$P \leq 0.05$ (LSD) & 8.05 & 0.73 & 2.39 & 0.55 & 1.44 & 0.64 \\
\hline \multicolumn{7}{|l|}{ Varieties } \\
\hline V1 & $19.57^{\mathrm{c}}$ & $1.01^{\mathrm{b}}$ & $7.02^{c}$ & $0.45^{\mathrm{c}}$ & $2.32^{\mathrm{b}}$ & 24.59 \\
\hline $\mathrm{V} 2$ & $41.96^{\mathrm{a}}$ & $1.95^{\mathrm{a}}$ & $14.18^{\mathrm{a}}$ & $0.66^{\mathrm{bc}}$ & $3.21^{\mathrm{a}}$ & 24.67 \\
\hline V3 & $37.75^{b}$ & $1.74^{\mathrm{a}}$ & $13.26^{\mathrm{ab}}$ & $0.71^{\mathrm{b}}$ & $2.78^{\mathrm{ab}}$ & 24.65 \\
\hline V4 & $36.55^{\mathrm{b}}$ & $1.96^{\mathrm{a}}$ & $12.93^{\mathrm{b}}$ & $0.96^{\mathrm{a}}$ & $3.20^{\mathrm{a}}$ & 24.49 \\
\hline$P \leq 0.05$ (LSD) & 3.52 & 0.26 & 1.14 & 0.23 & 0.51 & 0.49 \\
\hline $\begin{array}{c}\mathrm{LT}^{*} \text { Variety at } \\
\mathrm{P} \leq 0.05\end{array}$ & $* * *$ & ns & ns & ns & $* * *$ & ns \\
\hline
\end{tabular}

No interaction was discovered on dry shoot weight, fresh root weight, dry root weight, and SPAD value. No significant difference was found on shoot and root dry weight on the LT factor. However, there is significant value on varieties factor on shoot and root dry weight. V2, V3, and V4 were significantly different with V1 on shoot dry weight. V4 was significantly different with $\mathrm{V} 1, \mathrm{~V} 2$ and $\mathrm{V} 3$ on root dry weight, with no significant value on V2 with V3 and V1 with V2. SPAD value was significantly different on LT 1, LT 2, LT 4, and LT 5 with LT 6 . No significant differences were observed on the varieties factor for SPAD value. There was interaction on LED and varieties factor on shoot dry weight and shoot to root ratio on the other parameters. 

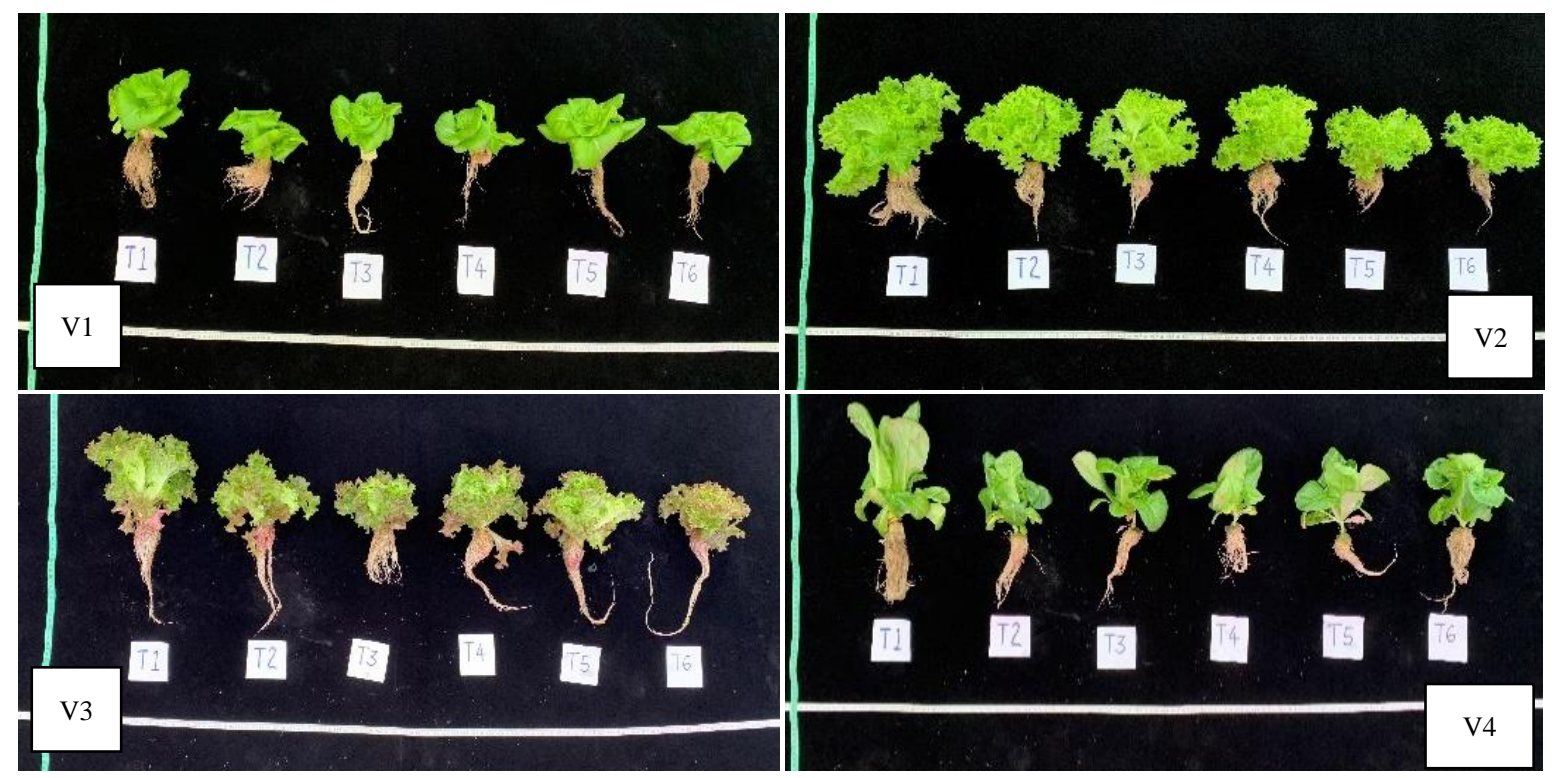

Figure 4. Variety effect on different light treatments at the seedlings production stage. The figure represents T1: LT1, T2:LT2, T3:LT3, T4:LT4, T5:LT5, and T6:LT6.

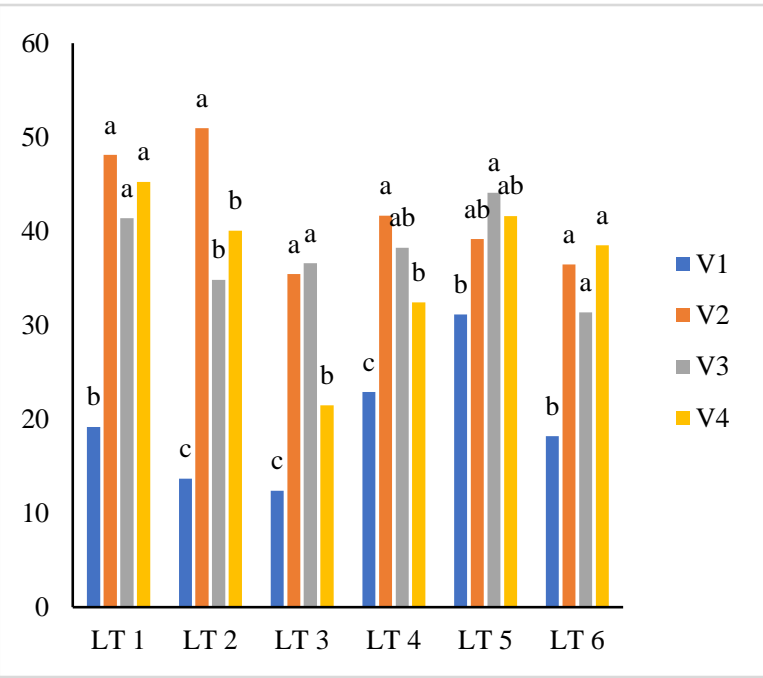

Figure 5. Interaction between LED formulation and lettuce varieties on shoot fresh weight. Means with different letter are significantly different at $P \leq 0.05$ respectively.

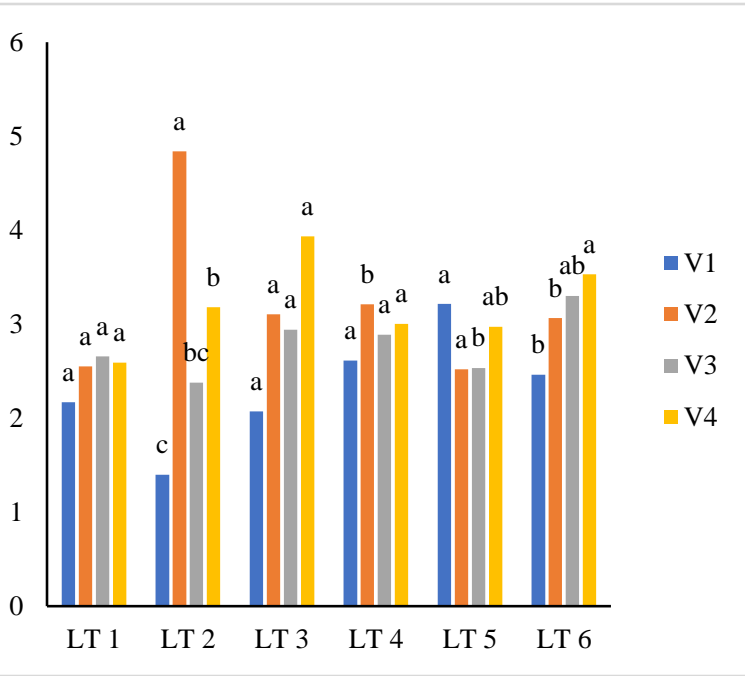

Figure 6. Interaction between LED formulation and lettuce varieties on Shoot to root ratio. Means with different letter are significantly different at $P \leq 0.05$ respectively.

LT 1 and LT 2 with V2 varieties have higher shoot fresh weight (Figure 5). LT 2 and LT 3 on V2 and V4 were significantly higher on the shoot to root ratio (Figure 6).

\section{Discussion}

Plant growth and development in the MARDI plant factory depend on the light spectrum. Optimum light intensity is needed for the early growth of planting, especially in the seedlings production area. High light intensity at early production has a limited effect on 
biomass at the early stage of planting (Kozai, 2013). This happened in this study, where no significant difference in plant biomass at different light spectrums occurs. However, for commercial purposes, total leaf area and fresh shoot weight are crucial. The total leaf area is visually the indicator of vegetables shape and size, while the fresh shoot weight is the production yield harvested for the plant. Changes in plant growth patterns were found in the production area on different LED and lettuce variety types.

The full spectrum LED is a broad-spectrum type of horticulture light source. This light source was widely used for plant factory and indoor farming production. Recently, various studies on narrow-spectrum light ratios have been done focusing on two curves of the photosynthetic chlorophyll absorption curve (Gupta \& Jatothu, 2013). The full spectrum LED shows good germination progress at seedlings production. However, the yield is significantly below compared to other LEDs in the production area. Red and blue LED spectrum with 5:1 and 1:1 ratio perform well on increasing the yield. The green spectrum on red and blue LED showed the same performance with 5:1 and 1:1 red and blue ratio on fresh yield and shot to root ratio. The green spectrum is valid on highly dense plants community in plant factories (Kim et al., 2004; Johkan et al., 2012), and the green photon is absorbed in lower leaves compared to the red and blue photons that are absorbed on upper leaves (Kozai, 2016).

Supplementing fans for better heat distribution inside the plant factory on each layer is required because the germination percentage at seedlings is deficient. Higher air current speed $(0.7 \mathrm{~m} / \mathrm{s})$ increases the growth uniformity of seedlings compared to lower speed $(0.3$ $\mathrm{m} / \mathrm{s}$ ) (Yokoi et al., 2007). Lowering the ambient temperature will increase the relative humidity; thus, it can increase the germination rate.

\section{Conclusions}

The nursery is a part of producing healthy and uniform size seedlings for better growth and yield. A suitable light source at the nursery is compulsory for better yield. The study's findings showed that light treatment with Red and Blue LED ratio of 5:1, 1:1 and Red, Blue, and Green LED ratio of 4:1:1 light arrangement on seedling's productions creates optimal growing conditions in the production area for butterhead and green coral lettuce in MPF. Further study on LED's water and energy use efficiency will be done soon for better production in MPF.

Funding: This work was funded by the Eleventh Malaysia Plan Development Project with a grant number of 21003004040001-2020.

Conflicts of Interest: No conflict of interest.

\section{References}

Barrow, C. J., Chan, N. W. \& Tarmiji, M. (2009). Issues and challenges of sustainable agriculture in the Cameron Highlands. Malaysian Journal of Environmental Management, 10(2), 89-114. 
Charlton, C. A. (1987). Problems and prospects for sustainable agricultural systems in the humid tropics. Applied Geography 7(2), 153-174.

Department of Agriculture (DOA) Malaysia (2019). Malaysian crop statistic (food crop sub-sector) 2019. Published by Agriculture Geospatial and Strategic Planning Statistic Centre, DOA.

Gupta, S. D. \& Jatothu, B. (2013). Fundamentals and applications of light emitting diodes (LEDs) in in vitro plant growth and morphogenesis. Plant Biotechnology Reports, 7, 211-220.

Johkan, M., Shoji, K., Goto, F., et al. (2012). Effect of green light wavelength and intensity on photomorphogeneis and photosynthesis in Lactuca sativa L. Environmental and Experimental Botany, $75,128-133$.

Jokinen, K., Sakka, L. E. \& Nakkila, J. (2012). Improving sweet pepper productivity by LED interlighting. Acta Horticulturae. 956, 59-66.

Kim, H. H., Goins G. D., Wheeler R. M., et al. (2004). Greenlight supplementation for enhanced lettuce growth under red- and blue-light-emitting diodes. HortScience, 39, 1617-1622.

Kozai, T. (2013). Plant factory in Japan - Current situation and perspectives. Chronica Horticulturae, 53(2), 811.

Kozai, T. (2013). Resource use efficiency of closed plant production system with artificial light: concept, estimation and application to plant factory. Proceedings of the Japan Academy Ser B Physical and Biological Sciences, 89(10), 447-461.

Kozai, T., (2012). Plant factory with artificial light (written in Japanese: Jinkoko-gata shokubutsu kojo). Ohmsya Publication, Chapter 27, 387-389.

Kozai, T., Genhua, N. \& Michiko, T. (2016). Plant factory: An indoor vertical farming system for efficient quality food production. Academic Press Elsevier.

Liu, W. K., Yang, Q. \& Wei, L. L. (2012). Light emitting diodes (LEDs) and their applications in protected horticulture as a light source. China Agriculture Science and Technology Publisher.

Massa, G. D., Kim, H.-H. \& Wheeler, R. M. (2008). Plant productivity in response to LED lighting. HortScience, 43(7), 1951-1956.

Mitchell, C.A., Both, A.J., Bourget, C.M., et al. (2012). LEDs: the future of greenhouse lighting. Chronica Horticulturae, 52(1), 6-11.

Morrow, R. C. (2008). LED lighting in horticulture. HortScience, 43(7), 1947-1950.

UN Comtrade Database. (2019). Lettuce Import and Export. Malaysia Report. https://comtrade.un.org/

Yokoi, S., Goto, E., Kozai, T., et al. (2007). Effects of planting density and air current speed on the growth and that uniformity of tomato plug seedlings in a closed transplant production system. Journal of Science and High Technology in Agriculture, 19(4), 159-166. 